\title{
Combined effect of the use of carbon fiber and seawater and the molecular structure on the tribological behavior of polymer materials
}

\author{
Zhiqiang WANG ${ }^{1,2, *}$, Jing $\mathrm{NI}^{1}$, Dianrong GAO ${ }^{3}$ \\ ${ }^{1}$ School of Mechanical Engineering, Hangzhou Dianzi University, Hangzhou 310018, China \\ ${ }^{2}$ State Key Laboratory of Fluid Power and Mechatronic Systems, Zhejiang University, Hangzhou 310058, China \\ ${ }^{3}$ College of Mechanical Engineering, Yanshan University, Qinhuangdao 066004, China \\ Received: 18 December 2016 / Revised: 03 April 2017 / Accepted: 29 April 2017 \\ (C) The author(s) 2017. This article is published with open access at Springerlink.com
}

\begin{abstract}
The combined effect of the use of carbon fiber and seawater and the molecular structure on the tribological behavior of various polymer materials under natural seawater lubrication was investigated. After the investigation, the wear morphology of the contact surface was observed by a laser scanning confocal microscope, and the texture of the wear scars and tracks were presented in 3D profiles. Moreover, the mechanism of mixed lubrication and wear resistance was analyzed. The results demonstrated that the friction coefficient of carbon fiber-reinforced polyetheretherketone (CFRPEEK) is the lowest and fluctuates at approximately 0.11. Moreover, the seven polymer materials in ascending order of friction coefficients are CFRPEEK, carbon fiber-reinforced polyamide-imide, polytetrafluoroethylene, polyoxymethylene, polyetheretherketone (PEEK), acrylonitrile butadiene styrene resin, and glass fiber-epoxy resin. More critically, the simultaneous incorporation of deposition, polymeric scrap, hydrophilic groups, and seawater resulted in a decrease in the friction and wear of polymer materials under seawater lubrication. This observation implies that a synergistic friction-reducing and wear-resistant effect exists between carbon fiber, seawater, and the molecular structure of PEEK. As a result, a highly effective polymer material was discovered, CFRPEEK, which has the lowest friction coefficient of 0.11 and lowest wear rate of $2 \times 10^{-5} \mathrm{~mm}^{3} \cdot(\mathrm{N} \cdot \mathrm{m})^{-1}$ among the polymer materials; this validates the selection of dual friction pairs for seawater hydraulic components.
\end{abstract}

Keywords: friction coefficient; wear; molecular structure; polymer materials; seawater lubrication

\section{Introduction}

With industrialization and population growth, the problems of resource shortage and environment pollution have intensified. Marine exploitation is the primary means of expanding human living space and facilitating the further development. Oceans, covering more than $71 \%$ of the earth's surface, form an abundant water resource. Natural water has become the most popular hydraulic transmission system medium in place of oil. However, the physical and chemical properties of seawater, such as low lubricity and high causticity, result in numerous challenges. Consequently, research into the tribological performance of friction pairs in seawater environment is critical for seawater hydraulic components.

Compared with metal, polymer materials exhibit higher performance in terms of self-lubrication, friction properties, and wear and corrosion resistance [1-3]. These advantages render them more adaptable to underwater environment. Therefore, a number of international scholars conducted numerous studies on the friction and wear characteristics of polymer materials. Chen et al. [4] prepared carbon fiber and

* Corresponding author: Zhiqiang WANG, E-mail: wangzq@hdu.edu.cn 
polyimide composites simultaneously reinforced with polytetrafluoroethylene (PTFE) and determined that the incorporation of polyimide (PI) and carbon fiber (CF) contributes toward significantly enhancing the wear resistance of PTFE. Dubey et al. [5] reported the effects of nanosized PTFE particles as a solid lubricant. The results demonstrated that PTFE particles significantly enhance the weld load, as well as antiwear and friction reduction properties. Ye et al. [6] used interrupted microscopy measurements to investigate the evolution of transfer film development for an ultra-low-wear PTFE nanocomposite.

Hedayati et al. [7] observed that semicrystalline pure polyetheretherketone (PEEK) coating exhibited higher hardness and lower adhesion strength, coefficient of friction, and wear rate than the amorphous one. Chen et al. [8] investigated the friction and wear behaviors of PEEK/PEI/PES alloys under dry sliding contact condition and reported that wear resistance of the alloys were considerably higher than those of pure polyetherimide (PEI) and polyarylethersulfone (PES). Tang et al. [9] researched on the tribological characteristics of carbon fiber-reinforced polyetheretherketone (CFRPEEK) sliding on $\mathrm{Si}_{3} \mathrm{~N}_{4}$ lubricated with water and determined that the sliding velocity has a higher effect on friction than pressure does. Rasheva et al. [10] reported that fiber orientation influences the mechanical performance and tribological properties of short-carbon fiber-reinforced PEEK materials. Chen et al. [11] investigated the tribological behaviors of CFRPEEK and observed that the incorporation of CF significantly enhances the wear resistance of PEEK under seawater lubrication.

Pihtili [12] prepared glass fiber-epoxy resin (GFER) composites and determined that the weight loss of the woven GFER composite increased with increasing load and speed. Basavarajappa and Ellangovan [13] suggested that $5 \%$ silicon carbide and $5 \%$ graphite filled the glass-epoxy composites exhibited remarkably high wear resistance. Siddhartha and Gupta [14] observed chopped glass fiber-reinforced composites to exhibit higher performance than bidirectional glass fiber-reinforced composites under abrasive wear situations. Suresha et al. [15] reported that silicon carbide-filled glass-epoxy (G-E) composite exhibits higher resistance to slide wear compared to plain G-E composites.

Difallah et al. [16] investigated the mechanical and tribological response of acrylonitrile butadiene styrene (ABS) polymer matrix filled with graphite powder and determined that the addition of graphite in ABS matrix lowers friction coefficient and wear. Huseyin et al. [17] researched on the tribological performance of industrial PAI in a cooling environment without air cooling and observed that the coefficient of friction marginally decreased and wear rates increased with increase in load and sliding speed.

Mergler et al. [18] reported that the friction coefficient of polyoxymethylene (POM) sliding against stainless steel starts at a relatively low level of approximately 0.2 and increases to higher values after $20 \mathrm{~h}$ of sliding owing to material transfer. Cho et al. [19] investigated the effect of surface texturing on the friction of POM and determined that the lowest friction coefficient was obtained with a $10 \%$ texturing density. Chaudri et al. [20] investigated the frictional performance of PBT + PTFE pin sliding against POM; the results indicated that the decrease in friction at higher loads is due to softening of the PBT pin by frictional heating.

Although the tribological behavior of polymer materials was investigated, the studies mainly focused on dry friction and pure water lubrication. These studies are focused on material modification of fillers; however, the combined effects of seawater and molecular structure of matrix and carbon fiber are seldom discussed. In the field of metal matrix composites, Bajwa et al. [21-23] investigated the wear and corrosion resistance properties of $\mathrm{Ni}$-base composite and the microstructure of electrodeposited coatings under water lubrication and nano-enhanced lubrication. They reported that the nickel composite of nanosized alumina exhibits the maximum corrosion resistance.

In the present study, tribological experiments of 316L against PTFE, PEEK, CFRPEEK, GFER, ABS resin, carbon fiber-reinforced polyamide-imide (CFRPAI), and POM under natural seawater lubrication were conducted by using an MMU-5G ring-on-disk friction and wear tester. In this study, the wear morphology and texture of the wear scars and tracks on the contact surfaces were investigated, and the mechanisms of mixed lubrication and wear resistance were analyzed. 


\section{Experimental details}

\subsection{Preparation of seawater and materials}

In this study, natural seawater sourced from China's Bohai Bay was prepared [24]. The $\mathrm{pH}$ and salinity of the seawater are 7.2 and $2.983 \%$, respectively. The test materials included PTFE, PEEK, GFER, ABS resin, CFRPAI, POM, and CFRPEEK. The main performance parameters are presented in Table 1 . All the specimens were washed in an ultrasonic ethanol bath for $15 \mathrm{~min}$ and then air-dried to ensure the cleanliness of material's surface.

\subsection{Test specimens}

The dimensions of the upper specimen ring and bottom specimen disk were $\Phi 26 \mathrm{~mm}$ (outer diameter) $\times$ $\Phi 20 \mathrm{~mm}$ (inner diameter) and $\Phi 43 \mathrm{~mm}$ (diameter) $\times$ $3 \mathrm{~mm}$ (height), respectively. The upper specimen ring and bottom specimen disk were fabricated from stainless steel 316L (the composition is presented in Table 2) and polymer, respectively. Stainless steel 316L was selected as the upper specimen ring in the present research as it is likely that tribological materials are suitable for the marine environment. Stainless steel 316L has remarkably high wear and corrosion resistance $[25,26]$ and is widely used to fabricate the friction components of seawater pumps and motors $[27,28]$. The properties of stainless steel $316 \mathrm{~L}$ is presented in Table 3.

\subsection{Friction and wear tests}

The experiment used ring-disk sliding contact to investigate the friction and wear properties of each friction pair, as illustrated in Fig. 1. The upper specimen rotated around its own central axis under the set load and speed, while the bottom specimen was held stationary. The specimens were set in the box, which was filled completely with seawater in order to realize the continuous sliding of the friction pairs' contact surfaces in seawater. The load is adjusted through manipulating the supply pressure of the hydraulic cylinder, and the rotational speed is adjusted through the frequency speed regulation system. The seawater temperature was measured by a temperature sensor installed beneath the contact surface of the bottom specimen.

Table 1 Properties of polymer materials.

\begin{tabular}{|c|c|c|c|c|c|c|c|}
\hline $\begin{array}{l}\text { Polymer } \\
\text { materials }\end{array}$ & $\begin{array}{l}\text { Density } \\
\left(\mathrm{g} / \mathrm{cm}^{3}\right)\end{array}$ & $\begin{array}{c}\text { Water absorption after } \\
24 \mathrm{~h} \text { immersion in water } \\
\text { at } 23^{\circ} \mathrm{C}(\%)\end{array}$ & $\begin{array}{l}\text { Heat distortion } \\
\text { temperature } \\
\left({ }^{\circ} \mathrm{C}\right)\end{array}$ & $\begin{array}{c}\text { Coefficient of } \\
\text { thermal expansion } \\
\left(10^{-5} /{ }^{\circ} \mathrm{C}\right)\end{array}$ & $\begin{array}{c}\text { Tensile } \\
\text { strength at } \\
23{ }^{\circ} \mathrm{C}(\mathrm{MPa})\end{array}$ & $\begin{array}{c}\text { Bending } \\
\text { strength at } \\
23^{\circ} \mathrm{C}(\mathrm{MPa})\end{array}$ & $\begin{array}{l}\text { Compressive } \\
\text { strength } \\
(\mathrm{MPa})\end{array}$ \\
\hline PTFE & 2.2 & 0.01 & 120 & 10.3 & 28 & 18 & 11 \\
\hline PEEK & 1.3 & 0.5 & 163 & 4.7 & 100 & 163 & 118 \\
\hline GFER & 1.8 & 0.04 & 260 & 0.4 & 210 & 397 & 310 \\
\hline ABS resin & 1.04 & 0.2 & 180 & 2.88 & 55 & 80 & 65 \\
\hline CFRPAI & 1.42 & 0.33 & 250 & 2.5 & 152 & 235 & 221 \\
\hline POM & 1.41 & 0.22 & 124 & 0.23 & 98 & 283 & 110 \\
\hline CFRPEEK & 1.4 & 0.06 & 315 & 1.5 & 220 & 298 & 240 \\
\hline
\end{tabular}

Table 2 Chemical composition of $316 \mathrm{~L}$ and $9 \mathrm{Cr} 18 \mathrm{Mo}$.

\begin{tabular}{cccccccccc}
\hline \multirow{2}{*}{ Stainless steel } & \multicolumn{1}{c}{ Composition (wt\%) } \\
\cline { 2 - 8 } & $\mathrm{C}$ & $\mathrm{Si}$ & $\mathrm{Mn}$ & $\mathrm{P}$ & $\mathrm{S}$ & $\mathrm{Ni}$ & $\mathrm{Cr}$ & $\mathrm{Mo}$ \\
\hline $316 \mathrm{~L}$ & 0.03 & 1 & 2 & 0.035 & 0.03 & $10-14$ & $16-18.5$ & $2-3$ \\
\hline
\end{tabular}

Table 3 Main performance parameters of 316L.

\begin{tabular}{cccccccc}
\hline $\begin{array}{c}\text { Stainless } \\
\text { steel }\end{array}$ & $\begin{array}{c}\text { Density } \\
\left(\mathrm{g} / \mathrm{cm}^{3}\right)\end{array}$ & $\begin{array}{c}\text { Modulus of } \\
\text { elasticity }(\mathrm{GPa})\end{array}$ & $\begin{array}{c}\text { Brinell } \\
\text { hardness }\end{array}$ & $\begin{array}{c}\text { Elongation } \\
(\%)\end{array}$ & $\begin{array}{c}\text { Thermal } \\
\text { conductance } \\
(\mathrm{W} /(\mathrm{m} \cdot \mathrm{k}))\end{array}$ & $\begin{array}{c}\text { Coefficient of } \\
\text { thermal expansion } \\
\left(10^{-6} /{ }^{\circ} \mathrm{C}\right)\end{array}$ & $\begin{array}{c}\text { Tensile } \\
\text { strength } \\
(\mathrm{MPa})\end{array}$ \\
\hline $316 \mathrm{~L}$ & 8.03 & 206 & 230 & 30 & 16.3 & 16 & $\begin{array}{c}\text { Yield } \\
\text { strength } \\
(\mathrm{MPa})\end{array}$ \\
\hline
\end{tabular}




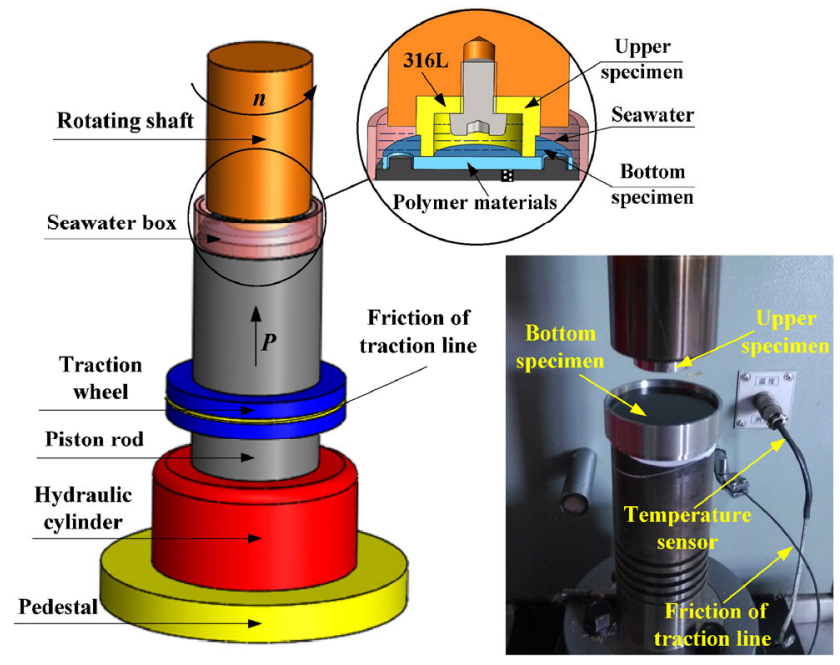

Fig. 1 Installation drawing of ring-on-disc configuration.

The experiments were performed with a rotational speed of $100 \mathrm{r} / \mathrm{min}(0.12 \mathrm{~m} / \mathrm{s})$, load of $100 \mathrm{~N}$, and period of $2 \mathrm{~h}$ and used seawater as the lubricant to simulate the actual working environment of the main dual friction pairs in the low-speed and high-torque hydraulic motor. All test parameters are displayed on the computer screen, and the computer recorded the curve of friction factor-time and temperature-time.

Subsequent to the friction and wear test, the depth of the wear track on the bottom specimen was measured using a digital thickness gauge (YG141D) to an accuracy of $0.01 \mathrm{~mm}$. The corresponding wear volume loss $\Delta V$ of the specimen was obtained by measuring the wear scar depth. Finally, the specific wear rate $\omega\left(\mathrm{mm}^{3} /(\mathrm{N} \cdot \mathrm{m})\right)$ was calculated from the volume loss by using the following equation:

$$
\omega=\frac{\Delta V}{2 \pi R n t F}
$$

where $\Delta V$ is the wear volume loss $\left(\mathrm{mm}^{3}\right), R$ is the mean radius of the upper specimens ring $(\mathrm{m}), n$ is the rotational velocity $(\mathrm{r} / \mathrm{min}), t$ is the wear time $(\mathrm{min})$, and $F$ is the load $(\mathrm{N})$.

\subsection{Observation of morphologies of worn surfaces}

The worn morphologies of the bottom specimens were observed using a laser scanning confocal microscope to understand the wear mechanism of PTFE, PEEK, GFER, ABS resin, CFRPAI, POM, and CFRPEEK under seawater lubrication. The texture of the wear scars and tracks were presented in 3D profiles to study its functional mechanisms further. The 3D profiles present the morphology of the contact surface, and the variations in surface topography were represented using various colors.

\section{Results}

\subsection{Analysis of friction and wear of polymer materials}

Figures 2 and 3 illustrate the variation of the friction coefficient of 316L against several polymers, with the test time. All the upper specimens were of $316 \mathrm{~L}$, while bottom specimens were of PTFE, PEEK, GFER, ABS resin, CFRPAI, POM, and CFRPEEK. The upper specimens rotated at $100 \mathrm{r} / \mathrm{min}$ speed and under $100 \mathrm{~N}$ load, while the bottom specimens were held stationary.

As illustrated in Fig. 2, the friction coefficient of 316L-PTFE increased rapidly from 0.1 to 0.17 in $10 \mathrm{~min}$ and then stabilized at approximately 0.17 . After $80 \mathrm{~min}$, it fluctuated around 0.15. The friction

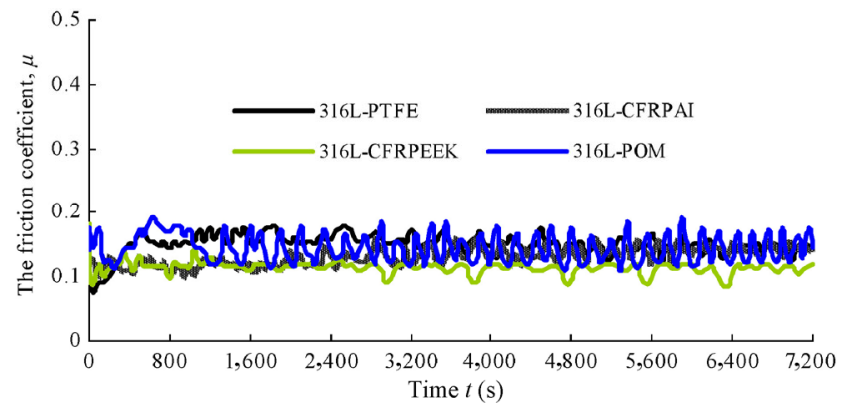

Fig. 2 Variation of the friction coefficient of 316L against PTFE, CFRPAI, CFRPEEK, and POM.

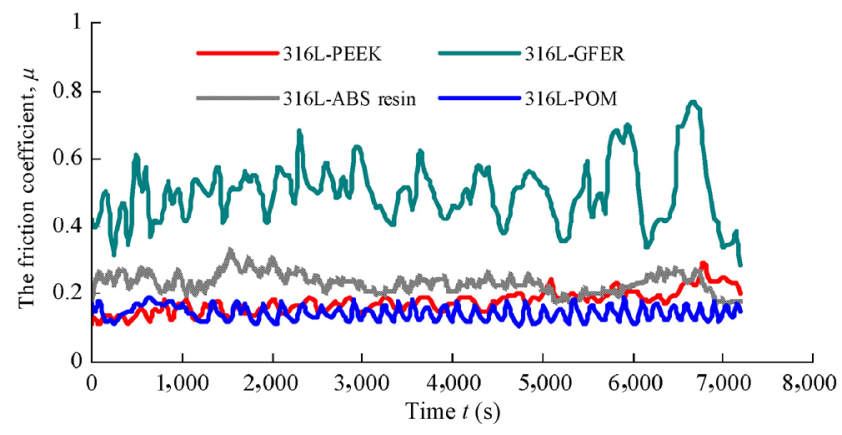

Fig. 3 Variation of the friction coefficient of 316L against PEEK, GFER, ABS resin, and POM. 
coefficient of 316L-PTFE is consistently higher than that of 316L-CFRPAI and 316L-CFRPEEK. The friction coefficient of 316L-POM fluctuated between 0.12 and 0.18 , which is marginally larger than that of 316L-PTFE. Meanwhile, the friction coefficients of 316L-CFRPAI and 316L-CFRPEEK fluctuated at approximately 0.1 over $25 \mathrm{~min}$. The two friction coefficients did not exhibit a running-in period. Then, the friction coefficient of 316L-CFRPAI gradually increased to become higher than that of the pair whose bottom specimen was CFRPEEK, while the coefficient of 316L-CFRPEEK fluctuated at approximately 0.11 . This is because of the molecular structure of PEEK, which has a higher proportion of hydrophilic groups than PAI. With the increase of the test time, the hydrophilic groups cause more water molecules to occupy the clearance. The flowing water better adapts to the action of external shearing force.

As Fig. 3 illustrates, the friction coefficient of 316LGFER fluctuated from 0.3 to 0.6 before $80 \mathrm{~min}$ and abruptly began to fluctuate from 0.3 to 0.9 when the friction coefficient of 316L-ABS resin fluctuated at approximately 0.25 . The friction coefficient of $316 \mathrm{~L}-$ PEEK increased gradually from 0.1 to 0.2 before $80 \mathrm{~min}$ and abruptly began fluctuating at approximately 0.3 . The friction coefficient of 316L-POM fluctuated from 0.12 to 0.18 , which is marginally lower than that of 316L-PEEK. Moreover, the fluctuation of the 316L-POM friction coefficient is the most regular and lowest in the four groups.

By analyzing the variation of the friction coefficient of the 316L pairs against the various polymer materials, the comparison of the various dual friction pairs were obtained as follows: 316L-CFRPEEK < 316LCFRPAI <316L-PTFE < 316L-POM < 316L-PEEK < 31 $6 \mathrm{~L}-\mathrm{ABS}$ resin $<316 \mathrm{~L}-\mathrm{GFER}$. Thus, it is determined that the friction coefficient of 316L-CFRPEEK is the lowest.

The specific wear rates of the seven types of polymers were calculated using Eq. (1), as illustrated in Fig. 4, to investigate the wear extent of the specimens.

Amongst all the specimens, CFRPEEK exhibited the lowest wear rate of $2 \times 10^{-5} \mathrm{~mm}^{3} \cdot(\mathrm{N} \cdot \mathrm{m})^{-1}$, while PTFE exhibited the highest wear rate of $75.5 \times 10^{-5} \mathrm{~mm}^{3} \cdot(\mathrm{N} \cdot \mathrm{m})^{-1}$. Moreover, the wear rate of CFRPEEK is approximately $2.65 \%$ that of PTFE.

The sequence of specific wear rate for the seven

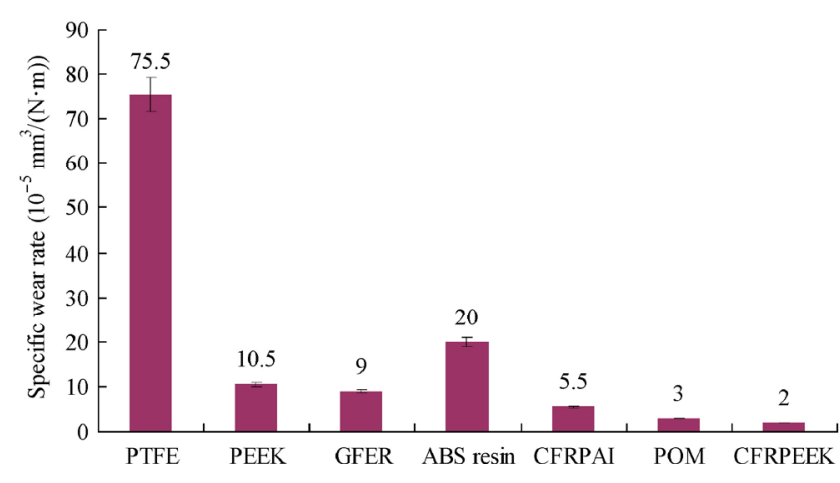

Fig. 4 The specific wear rates of the polymer materials.

polymer materials is: CFRPEEK $<$ POM $<$ CFRPAI $<$ GFER $<$ PEEK $<$ ABS resin $<$ PTFE. This indicates that CFRPEEK exhibits reasonable wear resistance in the process of friction and wear in seawater.

\subsection{Analysis of worn surfaces of polymer materials}

Figure 5 presents the worn surface micrographs of the various polymer materials. For comparison, the original surface morphologies are also provided. When compared with Fig. 5(a), Fig. 5(b) reveals that the worn surface of PTFE did not apparently exhibit scratch marks. However, particles of stainless steel 316L were observed on the worn surface, indicating that more extensive adhesive wear had occurred on the dual pair 316L-PTFE as a result of the wear test. Similar discovery was also reported in Refs. [29, 30]. Figure 5(d) illustrates that numerous small scratches appeared on the PEEK surface owing to wear, and the original morphology had disappeared. The Original GFER surface was grinded off and numerous small scratches on the worn surface (Fig. 5(f)). Moreover, the GFER surface was set with brown and white elements. The brown elements were dust particles from the worn GFER material, while the white elements were a few dust particles from the 316L. This observation indicates that the smearing and scratching phenomenon of adhesive wear exists on the surface of 316L-GFER as reported by Agrawal [31].

By comparing the original (Fig. 5(g)) with the worn ABS resin surface (Fig. 5(h)), it was determined that the surface had become smooth after the 316L-ABS resin wear test; however, numerous wide scratches were visible on the worn surface. White elements appeared on the ABS resin surface, which indicates 


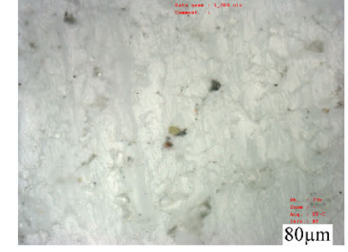

(a) Original morphology of PTFE

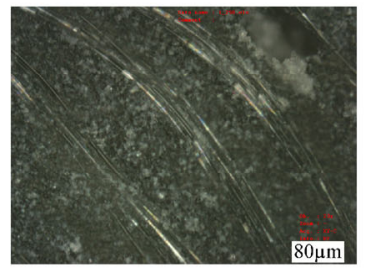

(e) Original morphology of GFER

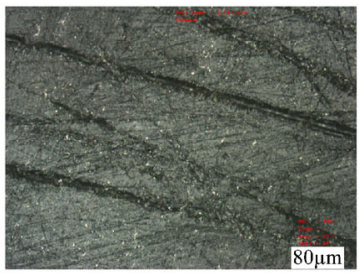

(i) Original morphology of CFRPAI

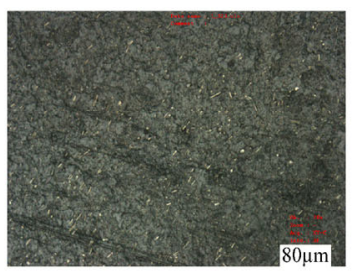

(m) Original morphology of CFRPEEK

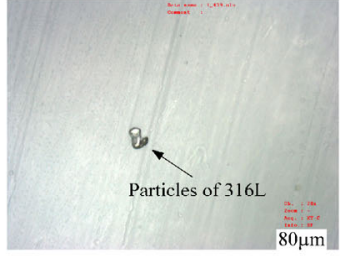

(b) Worn morphology of PTFE

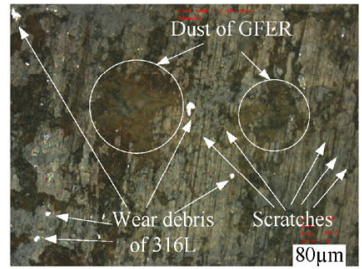

(f) Worn morphology of GFER

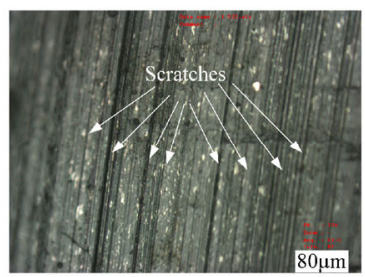

(j) Worn morphology of CFRPAI

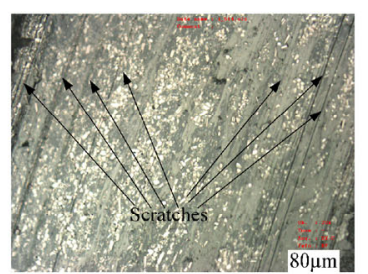

(n) Worn morphology of CFRPEEK

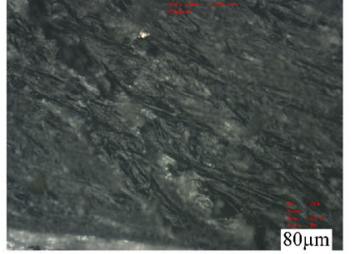

(c) Original morphology of PEEK

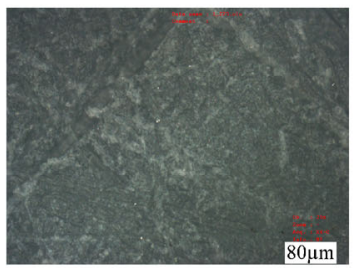

(g) Original morphology of ABS resin

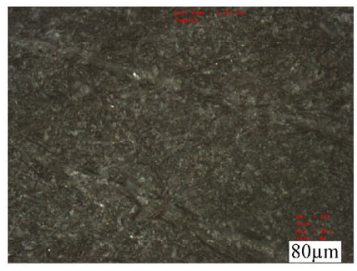

(k) Original morphology of POM

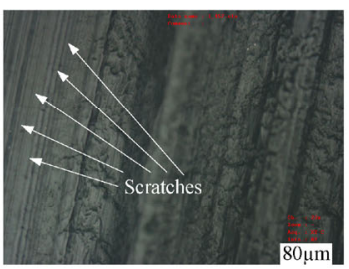

(d) Worn morphology of PEEK

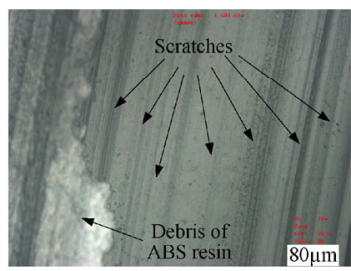

(h) Worn morphology of ABS resin

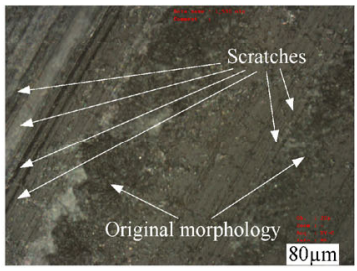

(1) Worn morphology of POM

Fig. 5 Original and worn surface morphologies of the various polymer materials.

that falling debris was embedded into the contact surface. This phenomenon is similar to that reported in Ref. [32]. Numerous small scratches appeared on the CFRPAI surface, as illustrated in Fig. 5(j), which reveals that scuffing phenomenon had occurred. Meanwhile, the POM surface indicates the occurrence of the scratch phenomenon in adhesive wear (Fig. 5(1)). The surface wear is not uniform, and the scratches display unequal widths. A part of the original morphology continues to be visible. In addition, the surface morphology of CFRPEEK observed in Figs. 5(m) and 5(n) exhibits a more uniformly worn surface and to a marginal extent exhibits scratch phenomenon with thinner scratches.

A laser microscope was used to scan the 3D morphology of the worn surfaces to analyze the friction and wear features of 316L against the various polymer materials and study their mechanism further. The result is presented in Fig. 6 .

Evidence of the plough-and-scratch phenomenon appears on the various types of polymer materials after wear, as illustrated in Fig. 6. Wear characteristics vary with the materials. The PTFE surface material is straightforwardly torn apart and forms the "prod" in the wear process owing to low strength and hardness of pure PTFE, as illustrated in Fig. 6(a). These prods repeatedly scrape the PTFE matrix, and this wear process increases the contact surface temperature. Then, plastic deformation appeared on the PTFE surface material and softened the matrix further, resulting in more extensive wear. The observation is consistent with those of few other researchers [33, 34]. Figure 6(b) illustrates that apparent grinded groove and "prods" appeared on the wear surface, which indicates that 


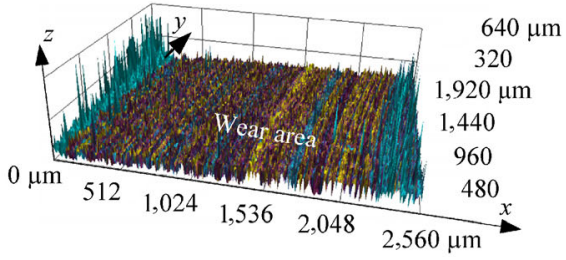

(a)

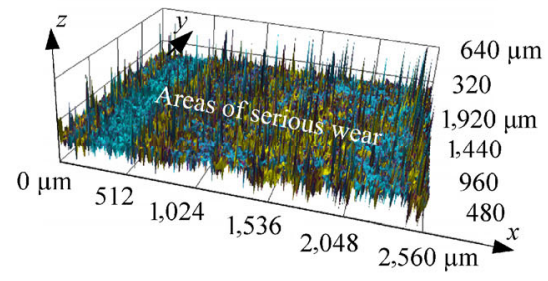

(c)

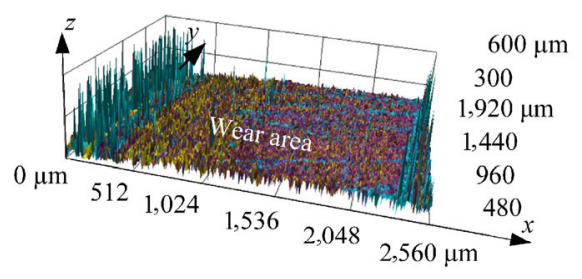

(e)

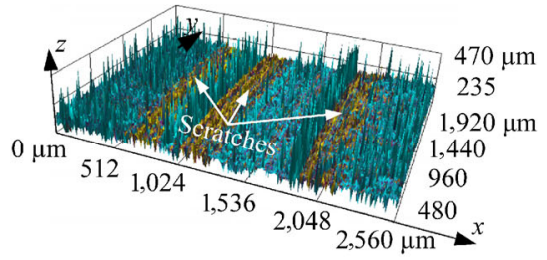

(b)

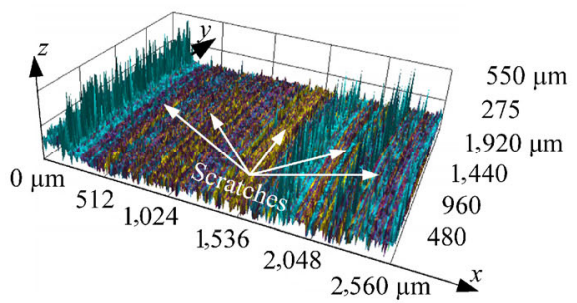

(d)

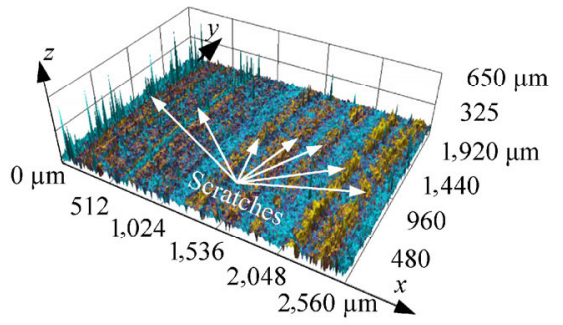

(f)

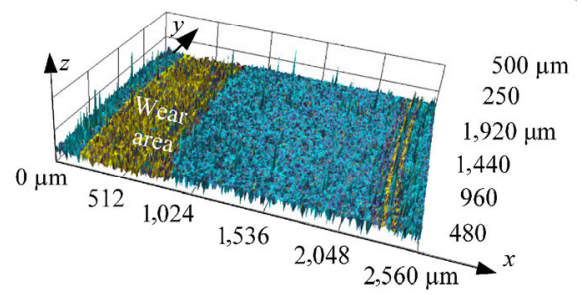

(g)

Fig. 6 3-D profiles of wear scars on the (a) PTFE, (b) PEEK, (c) GFER, (d) ABS resin, (e) CFRPAI, (f) POM, and (g) CFRPEEK surfaces after friction experiment lubricated by seawater.

the wear resistance of PEEK is not adequate.

When the bottom specimen is GFER, substantial "needles" appeared on the wear surface (Fig. 6(c)) because the bulges of the contact surface are cut off and the matrix wear debris and small particles are embedded into the surface during the process of wear. Numerous scratches and small grooves appeared on the contact surface (Fig. 6(d)); a number of "needles", which are caused by the wear particles, are visible. The CFRPAI wear surface is smoother than that of several of the abovementioned the above several specimens (Fig. 6(e)). Although there are "needles" and scratches, the scratches are fewer and smaller. Figure 6(f) illustrates that no apparent "needles" appeared on the POM wear surface; however, a number of wider scratches appeared on the surface.

A small-sized furrow or "needle" is visible on the 3D morphology of the worn surface (Fig. 6(g)) when the bottom specimen is CFRPEEK. A mark of light wear is visible in the linear or lamellate wear area on the contact surface in the direction of friction. Moreover, the worn surface is smooth without extensive scratches or grooves. This observation indicates that CFRPEEK has reasonable wear resistance, anti-attrition, anti-drag, and self-lubrication properties. A similar discovery was also reported in Refs. [11, 35, 36].

\subsection{Analysis of wear mechanism in polymer materials}

The analysis of the wear morphology reveals that the 
wear mechanisms of the selected polymer materials mainly include tiny plough, grinding, and plastic deformation, and the two or more phenomena may occur simultaneously. Therefore, the wear mechanisms of the seven types of polymers are varied.

More extensive adhesive wear had occurred on the surface of PTFE after the wear test. Numerous small scratches and an apparent grinded groove appeared on the wear surface of PEEK, which indicates that the plough and grinding phenomenon occurred. Moreover, evidence of the smearing and scratching phenomenon of adhesive wear is visible on the GFER surface. The smearing phenomenon appears to have occurred on the worn surface, and numerous wide scratches and small grooves were visible. Although the scuffing phenomenon appears to have occurred on the worn surface of CFRPAI, the scratches are fewer and smaller. Evidence of the scratch phenomenon in adhesive wear also appears on the surface of POM, and the wear surface is not uniform. However, the CFRPEEK surface displays a more uniform worn surface and evidence of occurrence of scratch phenomenon to a marginal extent.

In addition, it can be observed in Fig. 6 depicting the $3 \mathrm{D}$ wear that mechanical scratches were present on the contact surfaces of the polymer materials. Minute bulges on the rough surface of stainless 316L resemble relatively softer polymer materials, like machine surface of softer polymer materials micro cut by tools continuously. Moreover, floating debris that is suspended in the water box also results in the polymer materials of the bottom specimens in the experiment being cut during the process of friction and wear.

\section{Discussion}

\subsection{Mixed lubricating effect}

In this study, the investigation of the tribological behavior of polymer materials is mainly for determining the appropriate counter materials for the port-plate pair of the low-speed high-torque water hydraulic motor. Therefore, the experimental model is similar to the port-plate and the rotor end surface in the low- speed high-torque water hydraulic motor. According to our previous study [37], the residual pressing force of the port plate pair is marginal. Under low load, it is convenient to form and maintain a seawater film between the stainless steel 316L and polymer materials. As illustrated in Fig. 7, the clearance between the sliding surfaces at the beginning is filled with adequate water. As the test progresses, the contact surfaces gain more severe damage because the seawater film breaks down. Thus, debris is crushed or broken and peeled off from the polymer materials matrix. Then, the sliding surfaces of the friction pair are immersed in a mixed solution of seawater and debris, as illustrated in Fig. 8. The debris of the polymer materials and seawater play a positive role, exhibiting a selflubricating action and water lubrication in the process of friction and wear.

In addition, seawater exhibits higher performance. In the opinion of Chen $[8,38]$, seawater exerts a better influence on the sliding surfaces as result of the deposition of $\mathrm{Ca}^{2+}$ and $\mathrm{Mg}^{2+}$ in the forms of $\mathrm{CaCO}_{3}$ and $\mathrm{Mg}(\mathrm{OH})_{2}$, respectively, onto the surface. The lubricating fluid, including deposition, polymeric scrap, and seawater are the mixed suspension liquid, which exhibits superior lubrication as well as prevents direct contact between the frictional surfaces. It ultimately causes the decrease in friction and wear.

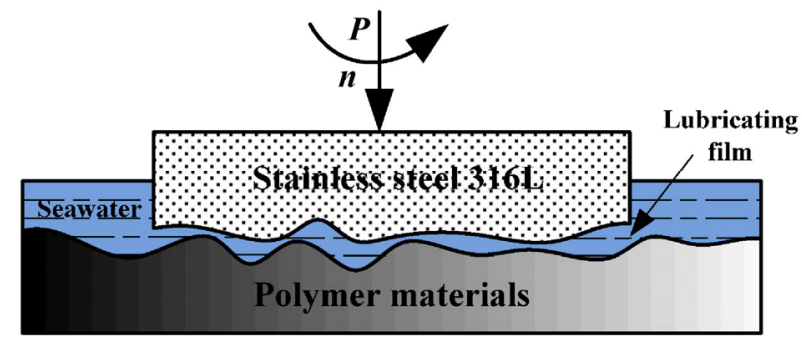

Fig. 7 Model of the beneficial effect of seawater.

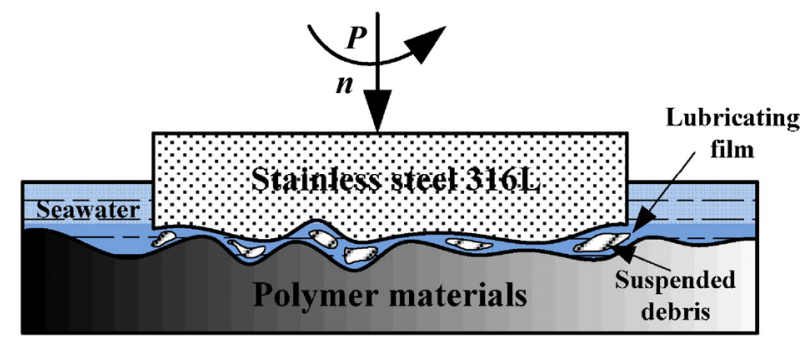

Fig. 8 Model of the beneficial effect of debris and seawater. 


\subsection{Molecular structure effect of polymer materials}

Another feasible reason lies in the fact that the molecular structure of polymer materials promotes hydrodynamic lubrication [39], which further enhances the lubricating effect of the friction pair. Figure 8 illustrates the molecular structure of the various polymer materials. As illustrated in the figures, PEEK, GFER, PAI, and POM contained carbonyl groups $(\mathrm{C}=\mathrm{O})$ and ether linkage $(-\mathrm{O}-)$, which are combined with water molecules by hydrogen bond [40]. Therefore, water molecules aggregated on the surface under the influence of these hydrophilic groups of PEEK, GFER, PAI, and POM, forming a more stable lubrication film. Meanwhile, Figs. 9(a) and 9(d) do not reveal polar hydrophilic groups in the PTFE and ABS resin molecular structures.

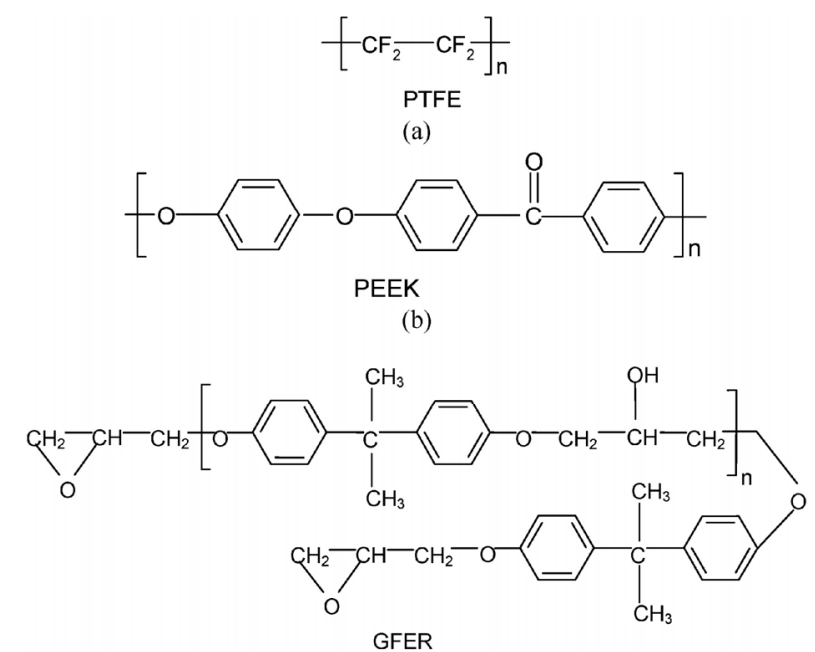

(c)

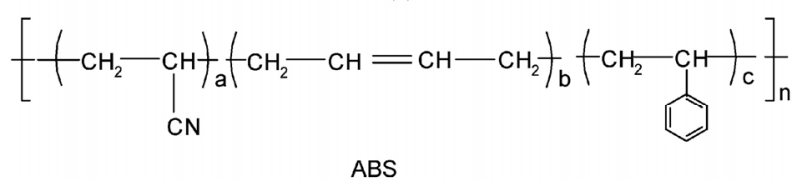

(d)

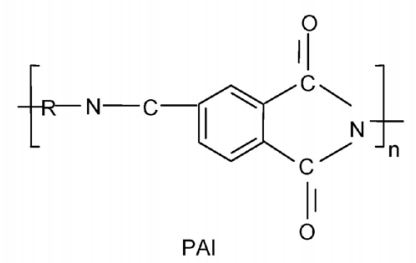

(e)

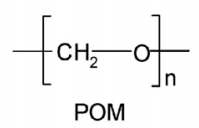

(f)

Fig. 9 Molecular structure of (a) PTFE, (b) PEEK, (c) GFER, (d) ABS resin, (e) PAI, and (f) POM.
Therefore, the wear resistance of PTFE and ABS resin is lower than that of PEEK, GFER, PAI, and POM. It is consistent with the calculation results of specific wear rates, as illustrated in Fig. 4.

\subsection{The carbon fiber effect}

Experimental results demonstrate that polymer materials based on carbon fiber exhibit highly effective friction and wear characteristics under seawater lubrication. With the increment of wear time, the more severe wear of CFRPEEK and CFRPAI is adequately restricted because, according to the reports of Chen [4, 41], the exposed carbon fiber carried the main load. Moreover, CFRPEEK has lower friction coefficient and more effective wear resistance than CFRPAI owing to the molecular structure of PEEK, which has a larger number of hydrophilic groups than PAI. The use of carbon fiber and seawater and the molecular structure produce a synergistic effect on the enhancement of the wear resistance of the polymer materials, which substantiates the apparent decrease in friction and wear of CFRPEEK.

\section{Conclusions}

Friction and wear experiments of the dual friction pairs in the study are conducted under seawater lubrication. From the results of the experiments, the following conclusions are drawn:

1. The friction and wear test results demonstrate that CFRPEEK has the lowest friction coefficient of 0.11 among the seven types of polymers. Moreover, it exhibits the lowest wear rate of $2 \times 10^{-5} \mathrm{~mm}^{3} \cdot(\mathrm{N} \cdot \mathrm{m})^{-1}$ followed by POM, CFRPAI, GFER, PEEK, ABS resin, and PTFE. The wear rate of CFRPEEK is approximately $2.65 \%$ that of PTFE.

2. The lubricating fluid in the process of friction and wear, including deposition and polymeric scrap and seawater, is a mixed suspending liquid, which exhibits superior lubrication as well as prevents direct contact between the frictional surfaces. Therefore, it ultimately causes the decrease in friction and wear.

3. The water molecules are aggregated on the surface by the hydrophilic groups of PEEK, GFER, PAI, and $\mathrm{POM}$, forming a more stable lubrication film. On the contrary, the wear resistance of PTFE and ABS resin is lower than that of PEEK, GFER, PAI, and POM 
owing to the absence of polar hydrophilic groups in the molecular structure of PTFE and ABS resin.

4. CFRPEEK exhibits effective friction and wear characteristics as well as self-lubricating properties in seawater, as compared to the rest of the polymer materials. This result is attributed to the use of carbon fiber and seawater and the molecular structure of PEEK, which produces a synergistic effect to enhance the friction and wear characteristics of polymer materials.

\section{Acknowledgements}

The work was financially supported by the National Natural Science Foundation of China (No. 51505111), the National Science Fund of Zhejiang Province (No. LQ16E050003), and Open Foundation of State Key Laboratory of Fluid Power and Mechatronic Systems (No. GZKF-201519).

Open Access: The articles published in this journal are distributed under the terms of the Creative Commons Attribution 4.0 International License (http:// creativecommons.org/licenses/by/4.0/), which permits unrestricted use, distribution, and reproduction in any medium, provided you give appropriate credit to the original author(s) and the source, provide a link to the Creative Commons license, and indicate if changes were made.

\section{References}

[1] Chauhan S R, Kumar A, Singh I. Sliding friction and wear behaviour of vinylester and its composites under dry and water lubricated sliding conditions. Mater Des 31(6): 27452751 (2010)

[2] Xie G Y, Sui G X, Yang R. Effects of potassium titanate whiskers and carbon fibers on the wear behavior of polyetheretherketone composite under water lubricated condition. Compos Sci Technol 71(6): 828-835 (2011)

[3] Wang J Z, Yan F Y, Xue Q J. Tribological behavior of PTFE sliding against steel in sea water. Wear 267(9-10): 1634-1641 (2009)

[4] Chen B B, Wang J Z, Yan F Y. Synergism of carbon fiber and polyimide in polytetrafluoroethylene-based composites: Friction and wear behavior under sea water lubrication. Mater Des 36: 366-371(2012)

[5] Dubey M K, Bijwe J, Ramakumar S. PTFE based nano- lubricants. Wear 306(1-2): 80-88 (2013)

[6] Ye J, Khare H S, Burris D L. Transfer film evolution and its role in promoting ultra-low wear of a PTFE nanocomposite. Wear 297(1-2): 1095-1102 (2013)

[7] Hedayati M, Salehi M, Bagheri R. Tribological and mechanical properties of amorphous and semi-crystalline $\mathrm{PEEK} / \mathrm{SiO}_{2}$ nanocomposite coatings deposited on the plain carbon steel by electrostatic powder spray technique. Prog Org Coat 74(1): 50-58 (2012)

[8] Chen J B, Guo Q, Zhang S, Wang X M, Shao X L. Research on friction and wear behaviors of PEEK/PEI/PES plastics alloys under sliding contact condition. Proc Eng 36(6): 285-291 (2012)

[9] Tang Q G, Chen J T, Liu L P. Tribological behaviours of carbon fibre reinforced PEEK sliding on silicon nitride lubricated with water. Wear 269(7): 541-546 (2010)

[10] Rasheva Z, Zhang G, Burkhart T. A correlation between the tribological and mechanical properties of short carbon fibers reinforced PEEK materials with different fiber orientations. Tribol Int 43(8): 1430-1437 (2010)

[11] Chen B B, Wang J Z, Yan F Y. Comparative investigation on the tribological behaviors of CF/PEEK composites under sea water lubrication. Tribol Int 52(3): 170-177 (2012)

[12] Pihtili H. An experimental investigation of wear of glass fibre-epoxy resin and glass Fibre-polyester resin composite materials. Eur Polym J 45(1): 149-154 (2009)

[13] Basavarajappa S, Ellangovan S. Dry sliding wear characteristics of glass-epoxy composite filled with silicon carbide and graphite particles. Wear 296(1-2): 491-496 (2012)

[14] Siddhartha, Gupta K. Mechanical and abrasive wear characterization of bidirectional and chopped e-glass fiber reinforced composite materials. Mater Des 35(35): 467-479 (2012)

[15] Suresha B, Chandramohan G, Rao P R S, Sampathkumaran $\mathrm{P}$, Seetharamu S, Venkateswarlu V. Friction and slide wear characteristics of glass-epoxy and glass-epoxy filled with SiCp composites. Indian J Eng Mater S 13(6): 535-541 (2006)

[16] Difallah B B, Kharrt M, Dammak M, Monteil G. Mechanical and tribological response of ABS polymer matrix filled with graphite power. Mater Des 34: 782-787 (2012)

[17] Huseyin U, Mehmet K, Abdullah M. Tribological performance of industrial polyamide-imide and its composite under different cooling conditions. J Polym Eng 32(3):201-206(2012)

[18] Mergler Y J, Schaake R P, Huis in't Veld A J. Material transfer of POM in sliding contact. Wear 256(3): 294-301 (2014)

[19] Cho MH, Park S. Micro CNC surface texturing on polyoxymethylene (POM) and its tribological performance in lubricated sliding. Tribol Int 44(7-8): 859-867 (2011) 
[20] Chaudri A M, Suvanto M, Pakkanen T T. Non-lubricated friction of polybutylene terephthalate (PBT) sliding against polyoxymethylene (POM). Wear 342: 189-197 (2015)

[21] Bajwa R S, Khan Z, Bakolas V, Braun W. Water-lubricated Ni-based composite ( $\mathrm{Ni}-\mathrm{Al} 2 \mathrm{O} 3, \mathrm{Ni}-\mathrm{SiC}$ and $\mathrm{Ni}-\mathrm{ZrO} 2)$ thin film coatings for industrial applications. Acta Metall Sin 29: 8-16 (2016)

[22] Bajwa R, Khan Z, Nazir H, Vivek C, Saeed A. Wear and friction properties of electrodeposited Ni-based coatings subject to nano-enhanced lubricant and composite coating. Acta Metall Sin 29: 902-910 (2016)

[23] Bajwa R S, Khan Z, Bakolas V, Braun W. Effect of bath ionic strength on adhesion and tribological properties of pure nickel and Ni-based nanocomposite coatings. J Adhes Sci Technol 30: 653-665 (2016)

[24] GB 17378.4-2007. The Specifications for Marine MonitoringPart 4: Seawater Analysis. Beijing: Standards Press of China, 2008.

[25] Henry P, Takadoum J, Bercot P. Tribocorrosion of 316L stainless steel and $\mathrm{TA}_{6} \mathrm{~V}_{4}$ alloy in $\mathrm{H}_{2} \mathrm{SO}_{4}$ media. Corros $\mathrm{Sci}$ 51(6): 1308-1314 (2009)

[26] Sun Y. Corrosion behaviour of low temperature plasm carburised 316L stainless steel in chloride containing solutions. Corros Sci 52(8): 2661-2670 (2010)

[27] Lu Y, Zhao Y Y, Bu G X, Shu P C. The integration of water vane pump and hydraulic vane motor for a small desalination system. Desalination 276(1-3): 60-65 (2011)

[28] Yu GZ, Nie SL, Liu HJ, Yin FL. Repair and experimental study on the key frictional pairs of DANFOSS water pump. Hydromechatronics Eng 40(19): 72-76 (2012)

[29] Wang H Y, Yan L, Gao D, Liu D J, Wang C, Sun L Y, Zhu Y J. Tribological properties of superamphiphobic PPS/PTFE composite coating in the oilfield produced water. Wear 319(1-2): 62-68 (2014)

[30] Wang J Z, Yan F Y, Xue Q J. Tribological behavior of PTFE sliding against steel in sea water. Wear 267(9-10): 1634-1641 (2014)

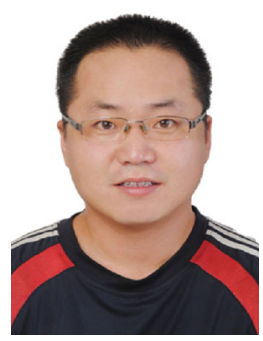

Zhiqiang WANG. He received his PhD degree from Yanshan University, China, in 2014. He joined School of Mechanical Engineering at Hangzhou Dianzi University from 2014. His current position is a lecturer of the school. His research interests include lubrication mechanism and friction and wear of seawater hydraulic motor. He has participated in
[31] Agrawal S, Singh K K, Sarkar P K. A comparative study of wear and friction characteristics of glass fibrereinforced epoxy resin, sliding under dry, oil-lubricated and inert gas environments. Tribol Int 96: 217-224 (2016)

[32] Tu CJ, Chen Z H, Chen D, Yan H G, He F Y. Tribological behavior and wear mechanism of resin-matrix contact strip against copper with electrical current. Trans Nonferrous Met Soc China 18(5): 1157-1163 (2008)

[33] Fan B L, Zu D L, Yang U L. Tribological properties of hybrid Kevlar/PTFE fabric reinforced phenolic composite filled with nano-alumina. Int Conf Mech Autom Control Eng 2010: 457-460 (2010)

[34] Unal H, Kurtulus E, Mimaroglu A, Aydin M. Tribological performance of PTFE bronze filled composites under wide range of application conditions. J Reinf Plast Comp 29(14): 2184-2191 (2010)

[35] Xie G Y, Sui G X, Yang R. Effects of potassium titanate whiskers and carbon fibers on the wear behavior of polyetheretherketone composite under water lubricated condition. Compos Sci Technol 71(6): 828-835 (2011)

[36] Wang J X, Gu M Y, Yang R. Wear properties and mechanisms of nylon and carbon-fiber-reinforced nylon in dry and wet conditions. J Appl Polym Sci 93(2): 789-795 (2004)

[37] Wang Z Q, Gao D R. Thrust collar parameter optimization of water hydraulic motor based on orthogonal test. Chin Mech Eng 24(24): 3360-3365 (2013)

[38] Chen B B, Wang J Z, Yan F Y. Frication and wear behaviors of several polymers sliding against GCr15 and 316 steel under the lubrication of sea water. Tribol Lett 42(1): 17-25 (2011)

[39] Klein J. Hydration lubrication. Friction 1(1): 1-23 (2013)

[40] Coles J M, Chang D P, Zauscher S. Molecular mechanisms of aqueous boundary lubrication by mucinous glycoproteins. Curr Opin Colloid Interf Sci 15(6): 406-416 (2010)

[41] Chen B B, Wang J Z, Liu N, Yan F Y. Synergism of several carbon series additions on the microstructures and tribological behaviors of polyimide-based composites under sea water lubrication. Mater Des 63(7): 325-332 (2014)

numerous research projects like "the National Natural Science Foundation of China", "the National Natural Science Foundation of Zhejiang Province", "the Foundation of State Key Laboratory of Fluid Power and Mechatronic Systems", and a few cooperative businesses projects. He has published more than sixteen papers in international and Chinese journals during the past three years. 


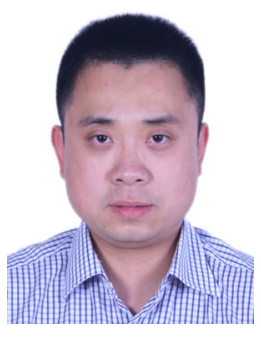

Jing NI. He received his $\mathrm{PhD}$ degree in 2006 from Zhejiang University. He joined School of Mechanical Engineering at Hangzhou Dianzi University from 2006. His current position is a professor and the deputy director of the School. His work has focused primarily on machine tool and surface engineering. He successively presided over

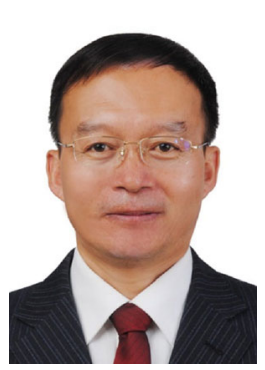

Dianrong GAO. He received his PhD degree in 2001 from Yanshan University. His current position is a professor of Yanshan University. During this period, he was invited to visit Louisiana State University as a senior visiting scholar in 2003. Then, he was invited to visit Abdus Salam International Centre for Theoretical Physics (ICTP) as a senior visiting scholar in 2014. He is a member of Chinese Mechanical Engineering Society, Chinese Society of Theoretical and Applied Mechanics, and participated in numerous research projects such as "the National Natural Science Foundation of China", "the National Natural Science Foundation of Zhejiang Province", and a few cooperative businesses projects. He has published more than 30 papers in Chinese academic journals, international journals, as well as international conferences. Moreover, he has been authorized fifteen national invention patents.

and Fluid Power Transmission and Control of China. His research areas of interest include CFD, PIV and new types of fluid components and devices, and antiwear and self lubrication. He successively presided and participated in numerous research projects like the National Basic Research Program of China (973), the National Natural Science Foundation of China, and few cooperative businesses projects. He has published more than 130 papers on Chinese academic journals, international journals, as well as international conferences. Moreover, he has been authorized twenty national invention patents. 